\title{
Numerical Integrations of the Primitive Equations by a Simulated Backward Difference Method*
}

\author{
By Taroh Matsuno \\ Geophysical Institute, Tokyo University, Tokyo \\ (Manuscript received 24 November 1965)
}

\begin{abstract}
A finite difference scheme for solving marching problems is designed. It is a two step iteration to simulate the backward difference method, i.e., first the tentative values at the later time stage are calculated by using the foreward difference and then the correction is made using these quantities. Applying this scheme to oscillatory equations, the high frequency oscillation is shown to be damped under certain conditions. Numerical integrations of the primitive equations for the so-called divergent barotrophic model were carried out by making use of this scheme. The result show that, because of an unbalanced initial state, gravity waves of fairly large amplitudes are initially generated. However, they are damped out with the lapse of time, while the quasi-geostrophic part of motions is kept less disturbed. For comparison, calculations were made for the same model and for the same initial conditions, by applying both the present method and the centered difference method commonly used. The two patterns thus calculated coincide in main features but differences are found in the distribution of divergence, especially near the boundary of the integration domain.
\end{abstract}

\section{Introduction}

One of the most difficult problems encountered in the numerical studies of large-scale motions based on the primitive equations, is how to suppress the short period oscillations which are introduced by artificial intial conditions or by some other causes. Many works have been made concerning the initialization of data (Charney, 1955; Hinkelmann, 1959; Phillips, 1960). They attempted to construct wind fields which balance geostrophically with the given pressure fields and to shut out the gravity wave component from the initial state. In fact they succeeded to reduce the amplitude of gravity oscillations to such a degree that meteorologically significant pressure systems were not seriously affected by the presence of gravity waves, so far as the pressure and wind fields were concerned. As to the horizontal velocity divergence or vertical velocity field, however, the filtering procedures commonly applied seem to be unsatisfactory, i.e., the vertical motion asso-

* Division of Meteorology, Contribution No. 144. ciated with gravity waves often amounts to comparable order of magnitude of that associated with quasi-geostrophic motions. This situation is not desirable if we are interested in the vertical motion associated with large scale pressure systems. It becomes serious if the effect of precipitation is to be taken into consideration. In order to get a better balanced wind field, a more refined method should be adopted. However, those procedures are complicated and iterations are usually needed. If we want to get a better balance, the computational labour for preparing initial conditions would be comparable with that for time integrations.

For this reason it is planned to design a computational scheme, which will filter out high frequency gravity oscillations in the process of time integration. At this point such a scheme would be most useful when finite differences in space coordinates are calculated on a lattice of variable mesh sizes. For instance, in a numerical study of formation of tropical cyclones, grid systems of variable mesh sizes are adopted in order to get a better resolution for the central por- 
tions of tropical cyclones and simultaneously to save the computational labors (Syōno, 1962). Ooyama (1962) reported that, by using such a scheme, small scale gravity waves generated in the central part of the domain did not propagate outward but accumulated there, because they could not be resolved in outer regions because of the comparatively large grid sizes. Consequently standing waves were formed and amplified. The present author (Matsuno, unpublished)also treated the similar problem and found that the unrealistic reflection occurs at the boundary between areas of the different mesh sizes. It seems, therefore, necessary to eliminate such artificial oscillations in the process of time integrations. Some numerical integration schemes have been proposed which have the desired character mentioned above (Lax and Wendroff, 1960; Phillips, 1962). However, those methods are not so suitable for our purpose. The Lax-Wendroff's scheme needs the second order differencing in space and, when it is applied to meteorological equations, it yields a much complicated form.

The Phillips scheme is designed for the different purpose and the damping effect for small scale waves is obtained as a by-product. This effect results from the uncentered differencing in space for advection terms and consequently the degree of damping depends on scale rather than frequency. Therefore his scheme does not sufficiently suppress gravity waves against meteorological waves. For this reason it is desired to design a simple integration scheme which serves as a filter, cutting off the high frequency part the keeping the low frequency part unmodified.

Mintz (1964) applied the present method to numerical integrations of the primitive equations for his general circulation model. Lilly (1965) tested this method in comparison with other methods. He paid attention mainly on the stability properties and accuracies of finite difference approximations. His result shows that the presented method is stable but less accurate compared with other methods, for example the four time level method proposed by Miyakoda. The present scheme was designed for filtering short period gravity oscillations, and Lilly's arguments did not cover this aspects. Kurihara (1965) discussed stabilities and filtering characteristics of various iterative and implicit methods, including the present method. However his work mainly concerns with theoretical analyses of computation schemes.

\section{Description of the present method and its characteristics}

As well known, the backward difference method possesses the desired character, i.e., if we adopt that method for solving an oscillatory system, the higher the frequency is (compared with the reciprocal of time increment), the more the amplitude is reduced with the lapse of time. However this method is not practical, because by approximating time derivatives by backward differences it becomes necessary to treat an implicit system, a system of simultaneous equations for unknown quantities at the later time stage. For this reason it is desired to devise a scheme which does not produce an implicit system retaining the features of high-cut filter. It is found to be possible to construct such a scheme by simulating backward difference method in the following manner. Consider the following equations for $N$ dependent variables ;

$$
\frac{\partial \xi_{i}}{\partial t}=\Omega_{i}\left(\xi_{j}\right) \quad(i, j=1,2, \cdots \cdots N)
$$

which are to be integrated. Here $\Omega$ 's are linear operators including finite differencing with respect to space coordinates.

If we adopt the backward difference method, the finite difference versions of the above equations are written as ;

$$
\xi^{(\tau+1)}-\xi^{(\tau)}=\Omega\left(\xi^{(\tau+1)}\right) \cdot \Delta t
$$

Here superscripts denote the time levels and $\Delta t$ is the time increment. The subscript $i$ which labels dependent variable will be omitted hereafter, for no confusion will occur. Since $\xi^{(\tau+1)}$ are involved in the right hand side, (2) are of implicit type. Then, if we replace them by some approximate values which are easily obtainable, the equations will turn to be of the explicit form. The simplest way to do so is to adopt a foreward difference method for calculating tentative values. In this case the whole scheme be- 
comes as follows;

$$
\begin{aligned}
& \xi_{*}^{(\tau+1)}-\xi^{(\tau)}=\Omega\left(\xi^{(\tau)}\right) \Delta t \\
& \xi^{(\tau+1)}-\xi^{(\tau)}=\Omega\left(\xi_{*}^{(\tau+1)}\right) \Delta t
\end{aligned}
$$

where $\xi_{*}^{(\tau+1)}$ is approximate value in the sense mentioned above. This scheme is very simple but works as a high-cut filter, as will be shown below. We shall assume that equations (1) are of pure oscillatory type, i.e., with suitable transformations they are written as ;

$$
\frac{D \xi_{n}}{D t}=i \omega_{n} \xi_{n}
$$

where $n$ labels $n$ 'th component of normal modes of which frequency is $\omega_{n}$. $n$ will be omitted when it is not necessary. $D / D t$ means either differential or some difference operators with respect to time. Taking the time increment $\Delta t$ as the unit of time, solutions of (4) by various methods take the form of

$$
\xi(\tau)=C \lambda^{\tau}
$$

$$
\lambda=\left\{\begin{array}{lc}
e^{i \omega}= & 1+i \omega-\frac{1}{2} \omega^{2}-\frac{1}{6} i \omega^{3}+O\left(\omega^{4}\right) \\
& (\text { Differential }) \\
1+i \omega= & 1+i \omega \\
\pm \sqrt{1-\omega^{2}}+i \omega= & (\text { Foreward difference) } \\
& (\text { Centered difference) } \\
1 /(1-i \omega)= & 1+i \omega-\omega^{2}-i \omega^{3}+O\left(\omega^{4}\right) \\
& (\text { Backward difference) } \\
1+i \omega(1+i \omega)= & 1+i \omega-\omega^{2} \\
& \text { (Present method) }
\end{array}\right.
$$

Hereafter we shall distinguish these roots by attaching subscripts $D, F, C, B$, and $P$ in the above order.

Values of various $\lambda$ 's for any $\omega$ and their loci on the complex plane are illustrated in Fig. 1. Here it is noted that $\lambda_{C}{ }^{\prime}$ is the second root for centered difference case usually called "computational mode" and $\lambda_{D}$, the root corresponding to differential operator, is located at such a point that the arc length between this point and $(1,0)$ is $\omega$. From

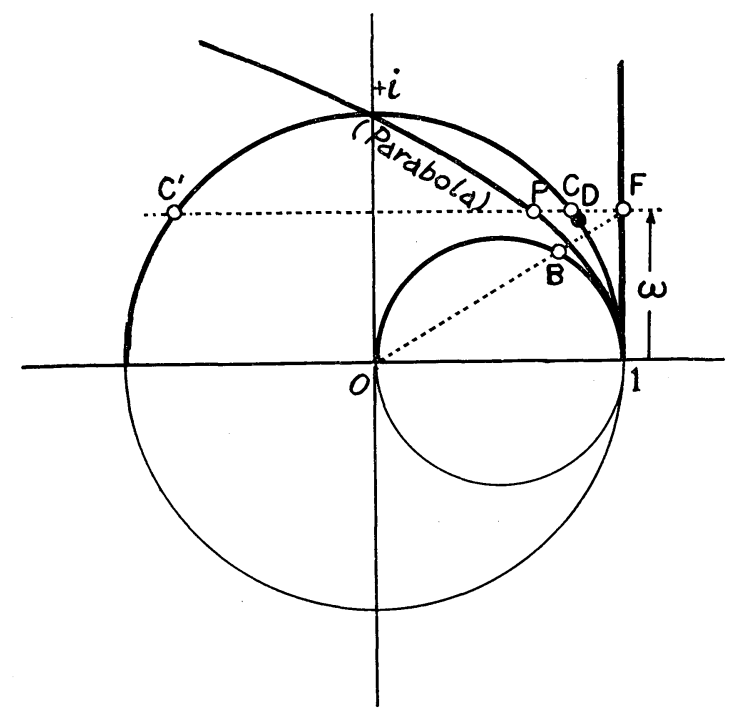

Fig. 1. Values of eigenvalues by various methods and their loci on the complex plane.

this figure it is observed that approximated frequencies, the phase angles of $\lambda$ 's are larger for $\lambda_{C}$ and $\lambda_{P}$ and smaller for $\lambda_{B}$ and $\lambda_{F}$ than that for the exact value $\lambda_{D}$. However, if the space truncation errors are taken into consideration, the above comparison becomes less significant. This is because space truncation errors which are involved in determining $\omega_{n}$ in (4) always tend to reduce the frequencies and these errors are much larger than the truncation error in the time differencing. We may therefore consider that all waves tend to slow down and variety of methods has little importance in this aspect.

Our attention, here, is focused to filtering characteristics of various methods. The absolute values of $\lambda$ 's as functions of $\omega$ are shown in Fig. 2. It is evidently shown that the present method works as a high-cut filter in the range $\omega<1 / \sqrt{2}$. We shall note that $\omega_{n}$ in eq. (4) is determined as the frequencies of normal modes, and usually we have a set of $\omega$ 's as many as the degree of freedom of the system. Then we have the maximum value for $\omega_{n}$ (in magnitude) and we can take a suitable value as $\Delta t$ so as to satisfy the condition ;

$$
\operatorname{Max}\left\{\omega_{n}\right\}<1 / \sqrt{2}
$$

Under this condition, the present method possesses the character of a high-cut filter. 


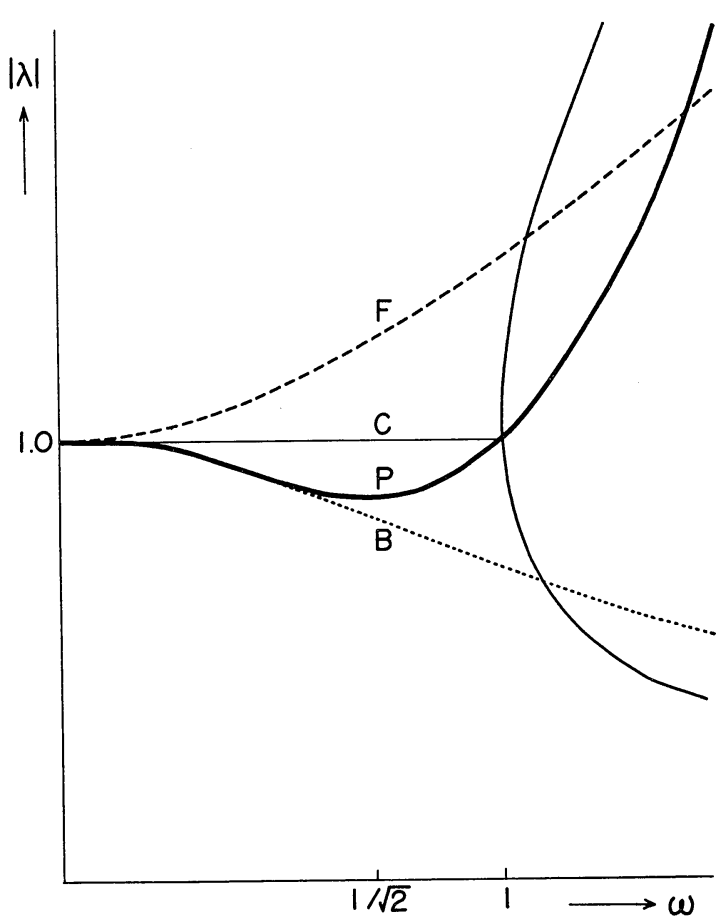

Fig. 2. Filtering characteristics of various methods.

The above condition implies the following limitation to the time interval; $\Delta t<1 /(\sqrt{2}$ $\left.\omega_{\max }\right)$ where $\omega_{\max }$ is the maximum frequency involved in the system.

We shall next consider the reason why this scheme has such a character. In the present method, the difference of the successive time levels is given as

$$
\begin{aligned}
\xi^{(\tau+1)}-\xi^{(\tau)} & =\left[\Omega \Delta t+(\Omega \Delta t)^{2}\right] \xi^{(\tau)} \\
& \simeq\left(\frac{\partial \xi}{\partial t}\right)_{\tau} \Delta t+\left(\frac{\partial^{2} \xi}{\partial t^{2}}\right)_{\tau} \Delta t^{2}
\end{aligned}
$$

Comparing (7) with the exact relation,

$$
\xi^{(\tau+1)}-\xi^{(\tau)}=\left(\frac{\partial \xi}{\partial t}\right)_{\tau} \Delta t+\frac{1}{2}\left(\frac{\partial^{2} \xi}{\partial t^{2}}\right)_{\tau} \Delta t^{2}+O\left(\Delta t^{3}\right)
$$

we note that, in the former the second derivative is doubled or half of it has an additional effect which works just like a diffusion term in time, so to say.

It should be noted that the (artificial) damping effect reduces the amplitudes of quasi-geostrophic waves, too. But this effect could be ignored under usual conditions as explained in the following. Usually meteor- ological waves (large scale pressure systems) have the period of a few days, i.e.,

$$
\omega \approx 2 \pi /\left(3 \times 10^{5} \mathrm{sec}\right) \fallingdotseq 2 \times 10^{-5} \mathrm{sec}^{-1}
$$

As the value of time increment, $\Delta t, 10 \sim 20$ minutes is taken so as to satisfy stability conditions for the shortest gravity waves resolved by the lattice of $300 \mathrm{~km}$ mesh. As a representative value we shall take $10^{3}$ seconds (about $15 \mathrm{~min}$ ). Then we get the amplification rate of meteorological waves as

$$
|\lambda|=1-10^{-4} \times 2
$$

The $1 / e$-folding time is calculated as

$$
T=\frac{1}{\ln |\lambda|} \fallingdotseq 0.5 \times 10^{4} \text { (steps) } \fallingdotseq 0.5 \times 10^{2} \text { (days) }
$$

This value seems to be large enough for time intergrations for short periods.

\section{Numerical integrations of the primitive equations by use of the proposed method}

In order to test how well the proposed method works for our purpose of eliminating gravity waves, actual numerical calculations were carried out for several simple patterns. The model adopted is the simplest one that has the basic features of our interests, i.e., a layer of homogeneous incompressible fluid with free surface. It is assumed that the fluid is flowing in a channel and a rectangular domain is taken for integration. The periodicity in the direction of channel is assumed. The equations of motion, the mass conservation equation and the boundary conditions are;

$$
\left.\begin{array}{l}
\begin{array}{l}
\frac{\partial \boldsymbol{v}}{\partial t}+\boldsymbol{v} \cdot \operatorname{grad} \boldsymbol{v}+f \boldsymbol{k} \times \boldsymbol{v}+\operatorname{grad} \phi=0 \\
\frac{\partial \phi}{\partial t}+\operatorname{div}(\phi \boldsymbol{v})=0
\end{array} \\
v \equiv(\boldsymbol{v})_{y}=0 \quad \text { at } y=0 \text { and } y=D \\
\boldsymbol{v}(0, y)=v(L, y), \phi(0, y)=\phi(L, y)
\end{array}\right\}
$$

Here notations are; $\boldsymbol{v}$; horizontal velocity vector,

$\phi$ : geopotential height of the top surface,

$\boldsymbol{k}$ : unit vector pointlng upward,

$f$ : the Coriolis parameter, 
$D$ : the width of the channel (in the $y$ direction),

$L$ : length of the domain in $x$-direction.

The finite differencing in space is one of the types, which conserve squared quantities so far as advection terms are concerned. For instance, the finite difference version of the equation for $u$ is,

$$
\begin{aligned}
\left(\frac{\partial u}{\partial t}\right)_{i j} & +\frac{1}{2 \Delta x}\left(\bar{u}_{i+1 / 2 j} \delta u_{i+1 / 2 j}+\bar{u}_{i-1 / 2 j} \delta u_{i-1 / 2 j}\right. \\
& \left.+\bar{v}_{i j+1 / 2} \delta u_{i j+1 / 2}+\bar{v}_{i j-1 / 2} \delta u_{i j-1 / 2}\right) \\
& -f v_{i j}+\frac{1}{2 \Delta x}\left(\phi_{i+1 j}-\phi_{i-1 j}\right)=0
\end{aligned}
$$

where symbols-and $\delta$ are defined, for examples

$$
\bar{u}_{i+1 / 2 j} \equiv \frac{1}{2}\left(u_{i+1 j}+u_{i j}\right), \quad \delta v_{i j-1 / 2} \equiv v_{i j}-v_{i j-1}
$$

The following numerical values are assigned for the parameters in order to simulate atmospheric conditions. Coriolis parameter $=15 \times 10^{-5} \mathrm{sec}^{-1}$, mean depth of the fluid layer $=3,000 \mathrm{~m}$, the acceleration of gravity $=9.8 \mathrm{~m}$ $\mathrm{sec}^{-2}$.

Horizontal grid distance $\Delta x$ and time increment $\Delta t$ are chosen $300 \mathrm{~km}$ and $15 \mathrm{~min}$. respectively, which satisfy the condition (6). For the sake of comparison, numerical integrations by use of the ordinary centered difference method (in time) were performed. Test calculations were carried out for the following cases ;

(A) A simple harmonic wave of large scale (wave length: 16 grid unit)

(A1) initial conditions: geostrophic (without divergent components)

(A2) initial conditions : balanced state obtained by conducting time integration for 24 hrs. by use of the present method

(B) A very small scale wave (wave length: 4 grids) No calculation was made by the centered difference method.

(B1) initial condition; geostrophic

(B2) initial condition; for the wind field same as (B1), but for the height disturbance just opposite to $(\mathrm{B} 1)$.
(C) A composition of two harmonic waves of rather small scale (wave length: 8 grids and 4 grids)

(C1) Same as (A1)

(C2) Same as (A2)

Case $\mathrm{A}$ and $\mathrm{B}$ were conducted to test filtering characteristics. In case $\mathrm{C}$ a rather extreme condition was taken in order to find out the discrepancy between this method and the centered difference method.

The results of numerical integrations are illustrated in Fig. 3 through Fig. 7. In these figures and also in the text hereafter, the proposed method will be refered as method $A$ and the centered difference method as method B.

Fig. 3 shows the time change of horizontal wind divergence at one point in the domain. The initial conditions were given as geostrophic wind (therefore non-divergent). It is clearly observed from the figure that gravitational waves generated at the initial instant are damped out after a few cycles in the case of method A, while by use of the method B the amplitudes of gravity waves remains
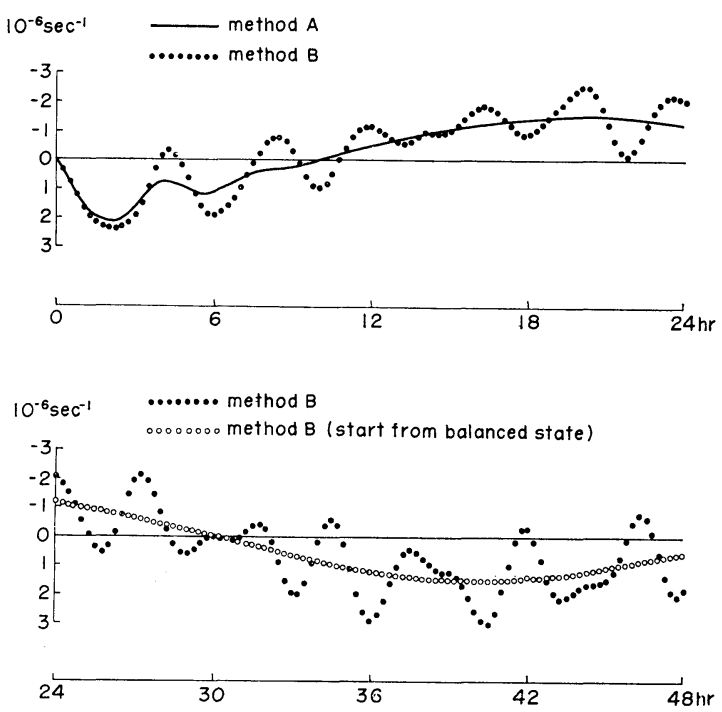

Fig. 3. Trace of horizontal velocity divergence at a certain point for case A (simple harmonic wave superposed on a uniform flow). Solid line: by method A.

Dotted line: by method B.

In the lower half the smooth curve of dots reprecents the values obtained by method $B$ but starting from the balanced state. 
almost unchanged in the whole integration period. It is important that the long trend of the dotted curve coincides with the solid line, which may be considered to represent the horizontal velocity divergence associated with quasi-geostrophic part of motions.

In the lower half of the figure two chains of dots are drawn. The rather wavy line shows the continuation of the upper figure while the smooth one is the result calculated by the same method B, but starting from the balanced state which was obtained as the result of integration over 24 hours by method A. The succeeding of the solid line is omitted in the lower half because it is so close to the smooth dotted line. It implies that method A and method B do not yield significant differences for slowly changing meteorological waves.

In Fig. 4 the height and horizontal velocity divergence fields at $24 \mathrm{hr}$. are shown, which were used as initial conditions for the integration by method B. The distribution of divergence are very smooth and reasonable in relation to the locations of large scale trough and ridge.

Fig. 5 shows the results of calculations by method A for the same initial wind fields but different height fields. The given wind fields are the very small scale waves (4 grid wave lengths in both directions) superposed on a basic flow. The initial height patterns are given in the two different ways; the one geostrophic, the other just opposite sense of

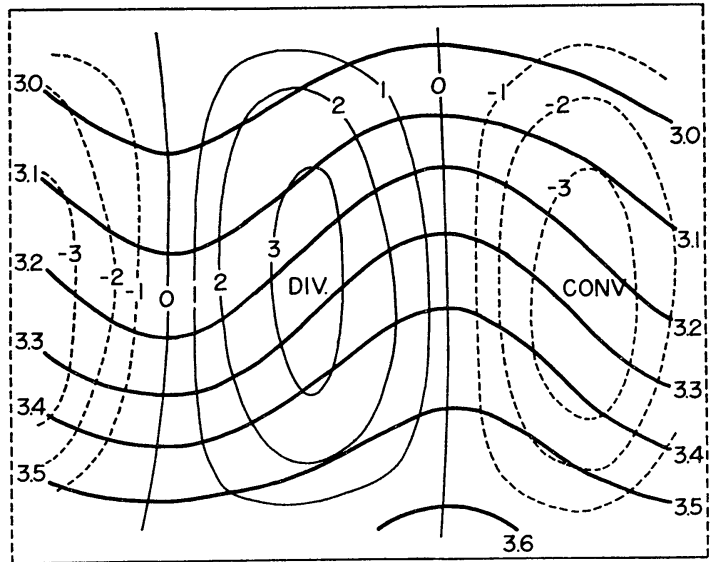

Fig. 4. Height and horizontal velocity Divergence for case A integrated for 24 hours by method $\mathrm{A}$.

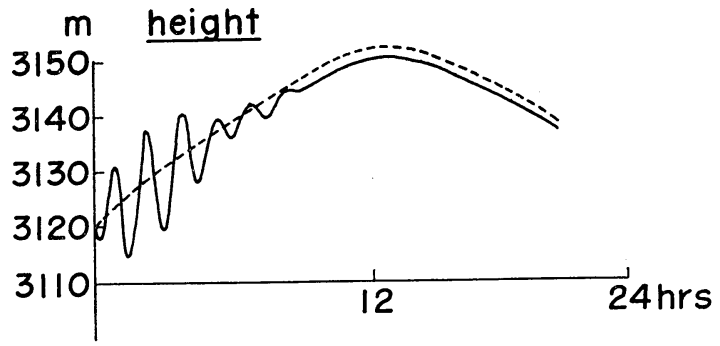

$\times 10^{-6} \mathrm{sec}^{-1}$ divergence

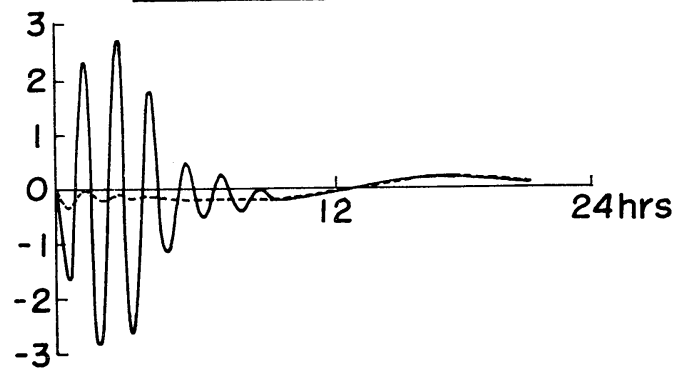

total energy $\frac{1}{100}$ of initial kinetic energy

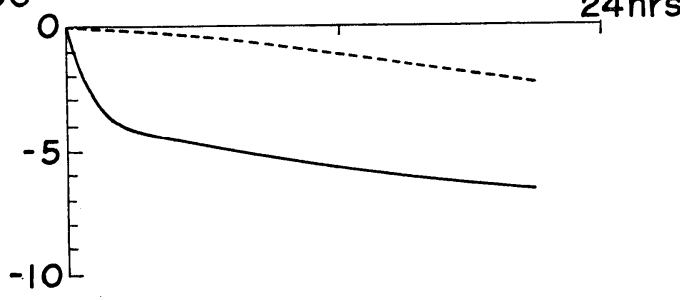

Fig. 5. Time change of height, horizontal velocity divergence and total energy at one point for case B. (very small scale wave). Solid line: Initial condition, opposite of geostrophic relation.

Dashed line: Initial condition, geostrophic.

geostrophic relation to wind disturbance. The basic current and height are in geostrophic balance. We can confirm from these figures that the filtering effect of the method $A$ is very large. Since this filtering effect results essentially from the truncation errors, the energy associated with short period oscillations is lost rapidly at the initial stage, and then the energy loss continues rather gradually. It is noteworthy that height patterns starting from the two utterly different state become very similer between the two, manifesting that pressure (height) fields adapted to the wind fields, since the scale of disturbances is very small. (It was quite unlucky 
that the values shown in the Fig. 5, were those at the neutral point of the disturbances at the initial moment.)

Fig. 6 and 7 show the results of computations for case $\mathrm{C}$ which were undertaken to check the difference of the two methods.

For that purpose, rather extreme situation is chosen. The domain of integration is four grid in width and the initial pattern consists of two wave components, their wave lengths being 8 and 4 in grid unit, respectively. The initial conditions were geostrophic and the integration was performed by the method A for 30 hours. During this interval the gravity waves were completely eliminated, as observed in Fig. 6. After then two computations were carried out, the one being continued by use of the method $\mathrm{A}$ and the other being carried out by method $\mathrm{B}$ by using the same data as initial state, which were considered to be free from noise (gravity waves). In Fig. 6 the time change of height and divergence at a certain point are shown. The specific total available energy is also shown, which was transformed in an equivalent quantity to the wind velocity.
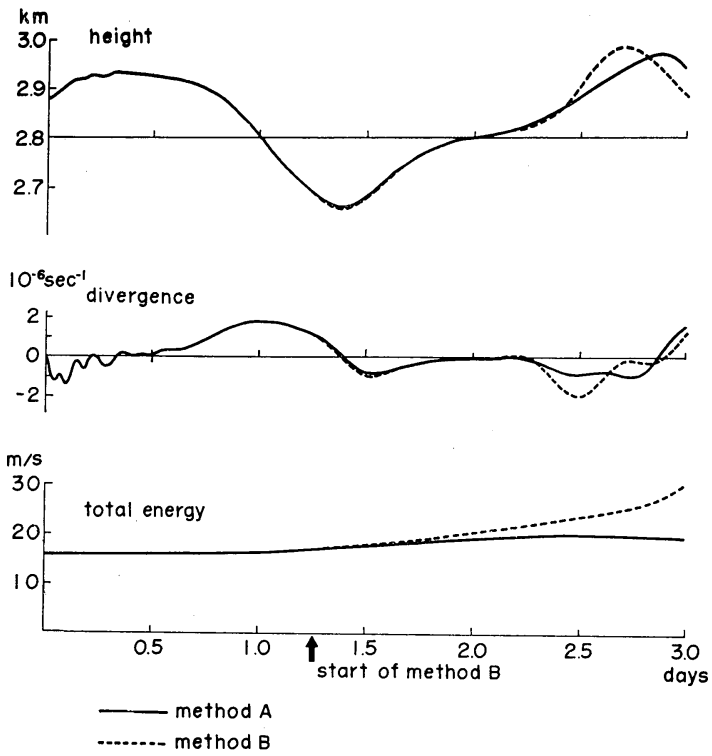

Fig. 6. Time change of height, divergence and total energy at one point (indicated in Fig. 7 by (O) for case $\mathrm{C}$ (Composition of two small scale waves).

Solid line: method A.

Dashed line: method B but starting from the same pattern at $T=30$ hours.
The solid lines are the trace obtained by method $\mathrm{A}$ and dashed line for method $\mathrm{B}$. The discrepancies of various quantities obtained by the two methods become noticeable in the later stage of integration.

As stated before, the model pattern chosen for this case was rather unrealistic, for it is intended to detect the differences and estimate the order of error.

In Fig. 7 the height and divergence fields obtained by the two different methods are shown. Unfortunately, by some mistakes, the data for 57 hr by method B are not available and the figure for $60 \mathrm{hr}$ is shown. Comparing these two figures one may note that the largest descrepancies found in the divergence fields near the boundary. It suggests that gravity waves are generated at the boundary (partly due to physical causes and partly by
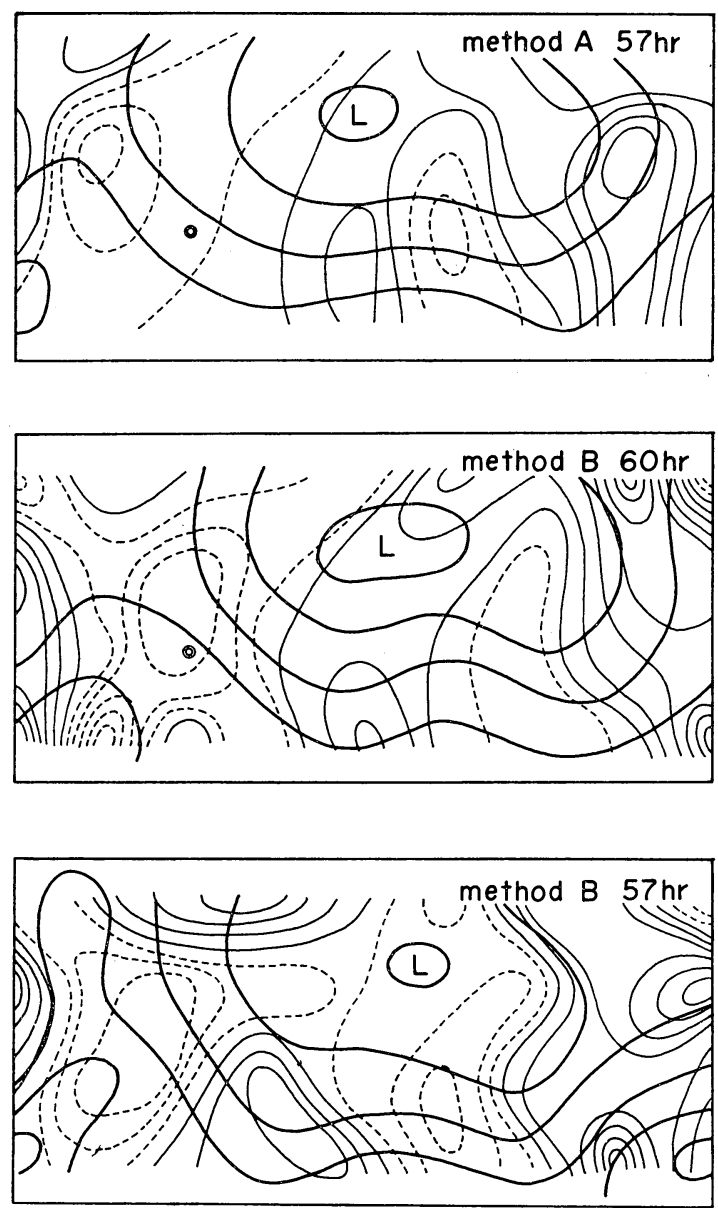

Fig. 7. Distributions of height and divergence computed by various methods. 
artificial boundary conditions), even if the gravity waves are eliminated from the initial state. The height field and the divergence in the central part of the domain do not show marked differences, while the bottom figure which is the result computed by method B starting from the geostrophic initial condition at $0 \mathrm{hr}$ shows very different features from the above two. Anyhow, under such an extreme condition the computation were carried out safely and showed fairly good agreements between the two methods. In the usual situations such small scale waves bear very little part of energy.

\section{Summary and conclusions}

In computation techniques of integrations of the primitive equations it is an important problem to suppress the unrealistic growth of short period gravity oscillations. It is one way to filtrate high frequency oscillations in the process of numerical integrations. A simple scheme which has such filtering characteristics is designed. It is a method to approximate the backward difference scheme by two steps, i.e. by using forward difference method the first prediction is made, then by use of the values thus obtained final values are calculated apparently like as backward difference method. The filtering characteristics of these procedures were discussed comparing with those of other methods costommarily adopted. It was shown that this method works as a good filter, which cut off high frequency part of the solutions but does not affect low frequency oscillations so much.

Performing numerical integrations of the primitive equations it was confirmed that by use of this scheme gravity oscillations are damped while large scale quasi-geostrophic motions are not disturbed significantly. However, energy of the large scale motions are lost very gradually because of artificial damping effect. It is supposed that this energy loss would be serious when one applys this scheme to very long term integrations of conservative systems. But if the physical damping due to viscosity exceeds artificial one we might neglect this effect.

Finally it must be remarked that filtering of gravity waves is possible only when their frequencies are sufficiently larger than those of quasi-geostrophic motions or there is a gap in spectrum of atmospheric waves. This is true in the middle and high latitudes under ordinary conditions, but not so in the equatorial areas as the present author pointed out (Matsuno, 1966).

\section{Acknowledgments}

This work was accomplished as a part of doctoral thesis under the guidance of Prof. S. Syono of Tokyo University, to whom the author would like to express his sincere gratitudes. The author is deeply indebted to Dr. K. Miyakoda who guided the author in basic problems of numerical integrations and gave him valuable suggestions. Thanks are due to Dr. A. Arakawa and Dr. K. Gambo, Japan Meteorological Agency for their stimulating discussions. Finally the author thanks to Miss M. Onozuka for typewriting the manuscripts and to Mr. Y. Fujiki for drawing figures.

\section{References}

Kurihara, Y., 1965: On the use of implicit and iterative methods for the time integration of the wave equation. Mon. Wea. Rev., 93, 33-43.

Lax, P. D. and Wendroff, 1960; Systems of conservation low. Communications on pure and applied mathematics, 13, 217-257.

Lilly, D. K., 1965: On the computational stability of numerical solutions of time-dependent nonlinear geophysical fluid dynamics problems.

Matsuno, T., 1966: Quasi-geostrophic motions in the equational area. J. meteor. Soc. Japan, 44, $1,25-43$.

Mintz, Y., 1964: Very long-term global integration of the primitive equations of atmospheric motion. Papers presented at the WMO/IUGG Symposium on the research and development aspects of long range forecasting. Boulder, Colorado, 1964.

Ooyama, K., 1962: Quarterly rep. of activities in J.N.W.P., 1962.

Phillips, N. A., 1962: Numerical integration of the hydrostatic system of equations with a modified version of the Eliassen finite-difference grid. Proceedings of the International Symposium on Numerical Weather Prediction in Tokyo, 1960. Meteorological Socity of Japan, 1962, 109-120.

Syono, S., 1962: A numerical experiment of the formation of tropical cyclones. ibid., 405-418. 


\section{プリミティブ方程式の時間積分の一方式}

松野太郎

東京大学理学部地球物理学教室

大気の大規模運動をプリミティブ方程式系で数値的ととりあつかう際, 人為的に生じた重力振動をとりさること は, 特に上昇流の場飞着目する時重要な問題である。このための一方法として, 重力振動と大規模運動との振動数の 差を利用し，高周波を通さないフィルターの性質をむった時間積分の方式を作った。はじめ飞前方差分方式によって 次の時間の諸量を暫定的飞求め, 次飞この值を用いて後方差分方式によって求め直すという方法である。この方法は 限られた条件の下で高周波振動を減衰させる性質をむつ。実際の大気モデル飞適用して数値積分を行なってみた。初 期条件として非発散の地衡風から出発するとかなり大きな振幅の重力振動を生ずるが（発散場についてみれば大規模 運動に伴うるのと同じ程度）時間積分をつづけるうちと減衰してしまい, 結局大規模運動の成分のみが残る。大規模 運動に対する隇衰効果は短期間では問題とすると足りない。 